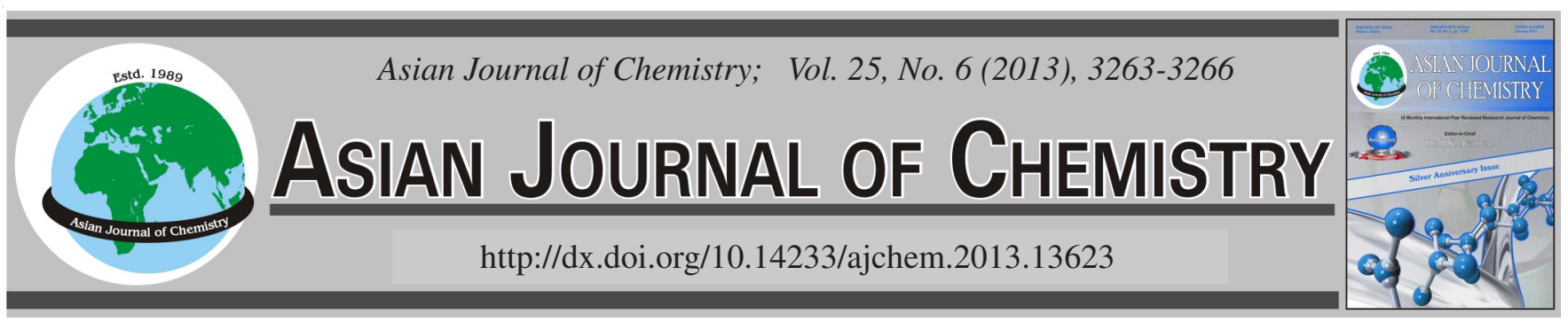

\title{
Sol-Gel Preparation of La Doped Strontium Titanate
}

WenJiE Zhang ${ }^{*}$, Xin Sun and Bo YANG

School of Environmental and Chemical Engineering, Shenyang Ligong University, Shenyang 110159, P.R. China

*Corresponding author: Tel: +86 24 83978969; E-mail: metalzhang@yahoo.com.cn

(Received: 18 February 2012;

Accepted: 17 December 2012)

AJC-12562

\begin{abstract}
La doped strontium titanate was prepared using sol-gel method. Pure strontium titanate has larger particle size than the La doped samples. The produced substances in the samples varied in accordance to La doping content. The La doped strontium titanate might be composed of $\mathrm{Sr}_{2} \mathrm{TiO}_{4}, \mathrm{Sr}_{1.9} \mathrm{La}_{0.1} \mathrm{TiO}_{3.95}, \mathrm{Sr}_{0.8} \mathrm{La}_{0.2} \mathrm{TiO}_{3}$ and a small per cent of $\mathrm{TiO}_{2}$ with respect to $\mathrm{La}$ content. The doping of $\mathrm{La}$ can improve the activity of the materials when La content is between 2-7\%. The strontium titanate doped with more than $10 \%$ La undergoes drastic activity declining. Adsorption rate of methyl orange on the two materials is not more than $3 \%$ after $2 \mathrm{~h}$. The doped strontium titanate has much improved activity than the sample without La doping. After $2 \mathrm{~h}$ of irradiation, methyl orange degradation rate is as high as $90.5 \%$ on the $5 \%$ La doped strontium titanate.
\end{abstract}

Key Words: La, Strontium titanate, Photocatalytic, Methyl orange.

\section{INTRODUCTION}

The aims of developing new photocatalyst and promoting activity of currently well studied materials are the two major research focuses. Perovskite structured composite metal oxides were well studied as a potential photocatalytic material due to high mobilization of charge carriers and the visible light responsible band structure ${ }^{1,2}$. Strontium titanate is a kind of perovskite structured material, which has been widely used as an electronic ceramic in various industrial applications ${ }^{3}$. As a functional material, strontium titanate has good photocatalytic activity and suitable band edge (3.2-3.8 eV) and has been used in photocatalytic field such as photochemical cell ${ }^{4}$, photocatalytic water splitting ${ }^{5}$ and degradation of organic pollutants ${ }^{6}$.

In order to obtain strontium titanate with high purity and quality, recently many kinds of preparation methods have been investigated $^{7-10}$. Metal ion doping is an effective method to improve activity of photocatalytic material. It is recognized that the doped metal ions can provide new energy level in the material and extend light responding spectrum ${ }^{11,12}$. In this paper, tetrabutyl titanate and strontium nitrate were used as initial materials in a sol-gel process to prepare La doped strontium titanate. The main focus of this paper was to study effects of La doping on phase composition, structure and photocatalytic activity of the strontium-titanium.

\section{EXPERIMENTAL}

In this paper, La doped strontium titanate was prepared by a modified sol-gel method. $10 \mathrm{~mL}$ acetic acid was mixed with $10 \mathrm{~mL}$ deionized water and then different amount of strontium nitrate and lanthanum chloride was dissolved in the former solution to obtain solution A, where molar ratio of $n(\mathrm{Sr}) /$ $n$ (Ti) was $1: 1.1 .7 \mathrm{~mL}$ of tetrabutyl titanate was dissolved in absolute ethanol under magnetic stirring for $10 \mathrm{~min}$ to obtain solution B with volume ratio of $\left[\mathrm{Ti}\left(\mathrm{OC}_{4} \mathrm{H}_{9}\right)_{4}\right]:\left(\mathrm{C}_{2} \mathrm{H}_{5} \mathrm{OH}\right)=1: 45$. After that, solution B was dropped into warm solution $\mathrm{A}$ at a constant speed under continuous vigorous magnetic stirring. A small amount of ethylene glycol was added into the mixture acting as stabilizer. The mixture was kept under stirring until a sticky sol formed. After $24 \mathrm{~h}$ of ageing at room temperature, the sol was dried at $110^{\circ} \mathrm{C}$ for $8 \mathrm{~h}$ to obtain a gel, followed by calcination of the gel at $800^{\circ} \mathrm{C}$ for $3 \mathrm{~h}$. The calcination products were grinded to obtain strontium titanate with different La doping content.

Characterization: Scanning electron microscope (SEM) images were taken on a HTACHI S-3400N scanning electron microanalyzer. The samples for SEM imaging were coated with a thin layer of gold film to avoid charging. The crystalline phases of the photocatalysts were measured by X-ray diffraction (XRD) with $\mathrm{D} / \mathrm{max}-\mathrm{rB}$ diffractometer using a $\mathrm{CuK}_{\alpha}$ radiation. FT-IR spectra of the samples were obtained using a Fourier transform infrared (FT-IR) spectrometer (WQF-410) with $\mathrm{KBr}$ pellets. The $\mathrm{N}_{2}$-adsorption and desorption of the samples were measured by F-Sorb 3400 specific surface area analytical instrument. Specific surface areas were calculated from $\mathrm{N}_{2}$ desorption isotherms, according to BET equation.

Adsorption and photocatalytic activity: Prior to photocatalytic experiment, methyl orange adsorption on the photo- 
catalyst in the dark was measured in the suspension of photocatalyst. $30 \mathrm{~mL}$ of $5 \mathrm{mg} / \mathrm{L}$ aqueous solution of methyl orange was mixed with $1000 \mathrm{mg} / \mathrm{L}$ photocatalyst in a $60 \mathrm{~mL}$ quartz reactor. The suspension was stirred magnetically for $25 \mathrm{~min}$ to reach adsorption equilibrium. After that, $5 \mathrm{~mL}$ of the suspension was taken out of the reactor and filtrated through a Millipore filter (pore size $0.45 \mathrm{~mm}$ ) to remove the photocatalyst. Finally, absorbency of the solution was measured by a $721 \mathrm{E}$ spectrophotometer at the maximum absorption wavelength of methyl orange $(468 \mathrm{~nm})$.

Subsequently, photocatalytic activities were evaluated in the above mentioned photocatalytic reactor. A $20 \mathrm{~W}$ UV lamp was located at the top of the reactor with the distance of $5 \mathrm{~cm}$. The lamp can irradiate UV light at wavelength of $253.7 \mathrm{~nm}$ with the intensity of $2200 \mathrm{~mW} / \mathrm{cm}^{2}$. The irradiation time in the subsequent experiments was set to $0.5 \mathrm{~h}$ if not indicated. The suspensions were filtrated through the Millipore filter before measuring.

\section{RESULTS AND DISCUSSION}

SEM images of strontium titanate doped with different content of La are shown in Fig. 1. The samples present various surface morphologies as the factor of La doping content. Although all the samples have fairly rough surface morphology, the pure strontium titanate has noticeable larger particle size than the La doped samples. Surface areas of the samples containing $0,1,5$ and $15 \% \mathrm{La}$ are $9.0,20.3,36.0$ and $22.3 \mathrm{~m}^{2}$ $\mathrm{g}^{-1}$, respectively. The particle size shrinkage with increasing La content leads to even rough surface morphology and high surface area, which is beneficial to adsorption and photocatalytic activity ${ }^{13}$.
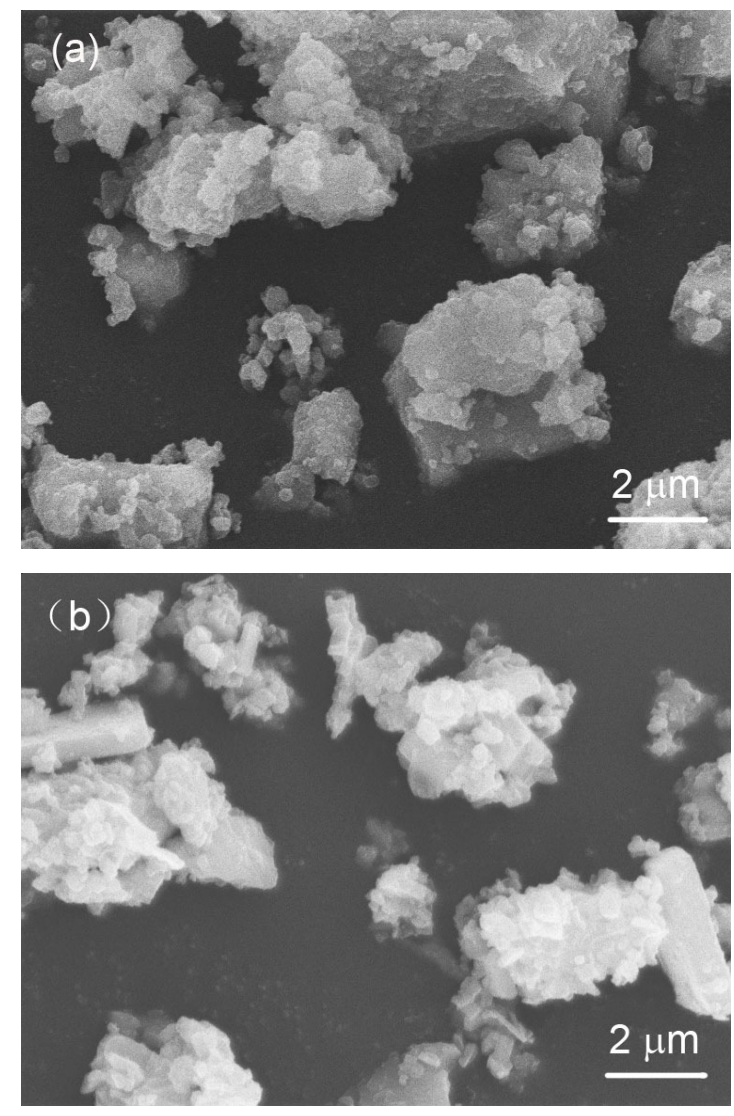
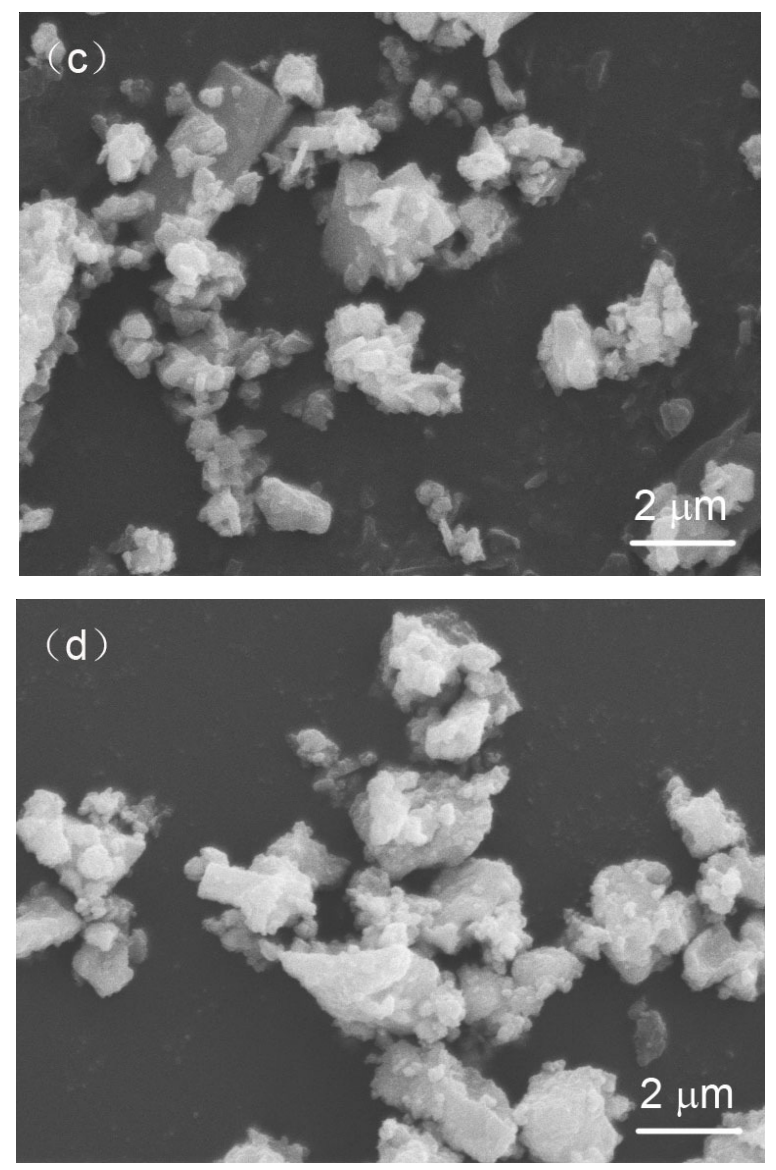

Fig. 1. SEM images of strontium titanate doped with different content of La (a: $0 \%$, b: $1 \%$, c: $5 \%$, d: $15 \%$ )

Fig. 2 illustrates XRD patterns of strontium titanate doped with different content of La. The substances in the produced samples varied in accordance to La doping content. When La content is $1 \%$, the XRD pattern is the same to that of pure strontium titanate. The samples are composed of $\mathrm{Sr}_{2} \mathrm{TiO}_{4}$ and $\mathrm{TiO}_{2}$. As calculated using peak intensities of the two phases, volume percentages of the two phases are 84.5 and $15.5 \%$. The main substance in the samples is $\mathrm{Sr}_{2} \mathrm{TiO}_{4}$.

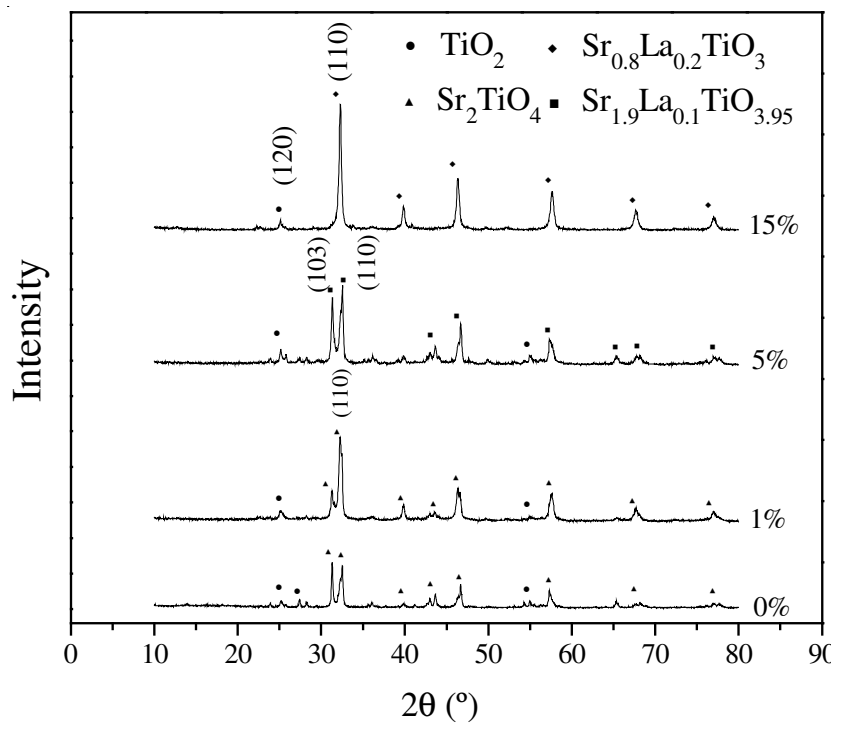

Fig. 2. XRD patterns of strontium titanate doped with different content of La 
When La content increases to $5 \%$, diffraction peaks of $\mathrm{Sr}_{2} \mathrm{TiO}_{4}$ nearly disappear and a new substance $\mathrm{Sr}_{1.9} \mathrm{La}_{0.1} \mathrm{TiO}_{3.95}$ takes place. A small amount of $\mathrm{TiO}_{2}$ also exists in the sample. The volume percentages of $\mathrm{Sr}_{1.9} \mathrm{La}_{0.1} \mathrm{TiO}_{3.95}$ and $\mathrm{TiO}_{2}$ are 89.4 and $10.6 \%$, respectively. In the sample containing $15 \%$ of $\mathrm{La}$, another new substance, $\mathrm{Sr}_{0.8} \mathrm{La}_{0.2} \mathrm{TiO}_{3}$ takes place of $\mathrm{Sr}_{1.9} \mathrm{La}_{0.1} \mathrm{TiO}_{3.95}$. Low amount of $\mathrm{La}$ can enter the crystallite structure of strontium titanate and does not alter the structure of the material. However, excessive amount of La ions may substitute the $\mathrm{Sr}$ ions in the crystallite structure and makes changes to the perovskite structured material.

FT-IR spectra of the strontium titanate doped with different content of La are shown in Fig. 3. There is no adsorption after $2000 \mathrm{~cm}^{-1}$, indicating that organic substances decomposed totally during high temperature calcination. The adsorption peak around $1560 \mathrm{~cm}^{-1}$ represents bending vibration of $-\mathrm{OH}$ in $\mathrm{H}_{2} \mathrm{O}$ that was adsorbed on surface of the sample ${ }^{14}$. The adsorption peak situated at $1084 \mathrm{~cm}^{-1}$ is assigned to vibration of $\mathrm{La}-\mathrm{O}$ and the peak at $1030 \mathrm{~cm}^{-1}$ is assigned to vibration of $\mathrm{Sr}-\mathrm{O}$ bond. The adsorption peak appeared at $489 \mathrm{~cm}^{-1}$ can be ascribed to be bending vibration of Ti-O-Ti ${ }^{15}$. The results are in accordance to composition revealed by XRD analysis. As indicated before, the La doped strontium titanate are composed of $\mathrm{Sr}_{2} \mathrm{TiO}_{4}, \mathrm{Sr}_{1.9} \mathrm{La}_{0.1} \mathrm{TiO}_{3.95}, \mathrm{Sr}_{0.8} \mathrm{La}_{0.2} \mathrm{TiO}_{3}$ and a small percent of $\mathrm{TiO}_{2}$. The La-O, Sr-O and Ti-O-Ti bonds are representatives of the produced substances.

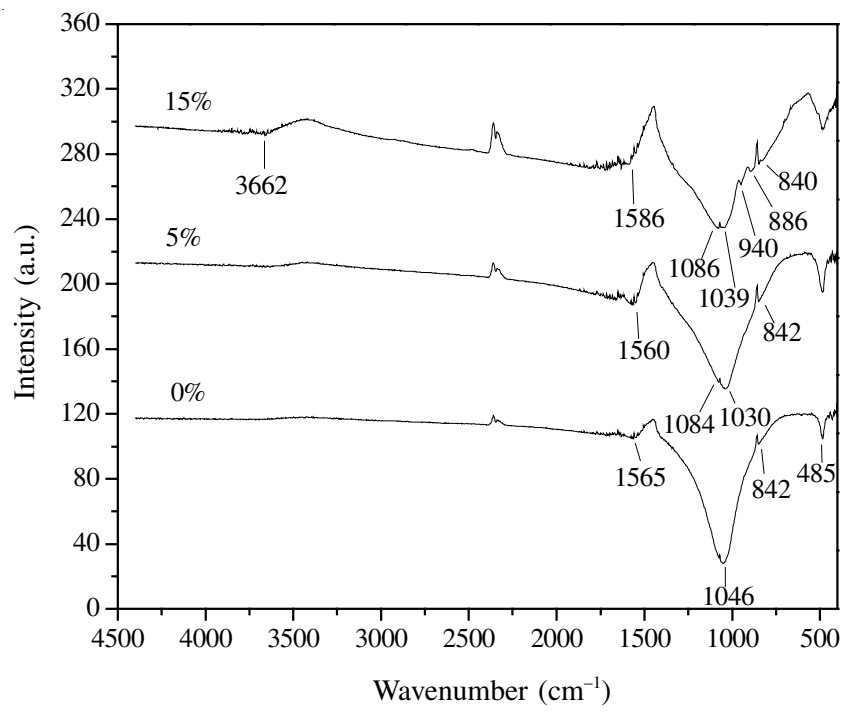

Fig. 3. FT-IR spectra of strontium titanates doped with different content of $\mathrm{La}$

The content of doped La has important influence on photocatalytic activity of the strontium titanate (Fig. 4). The doping of La can improve the activity of the materials when La content is between 2-7\%. The doped La can provide new energy level in the materials and extend the lifetime of photogenerated electrons and holes. The increasing surface area after La doping can also help on promoting photocatalytic activity. The reason is that the produced substances are different with the variation of La content. Obviously, these substances have different activity for degradation of methyl orange.

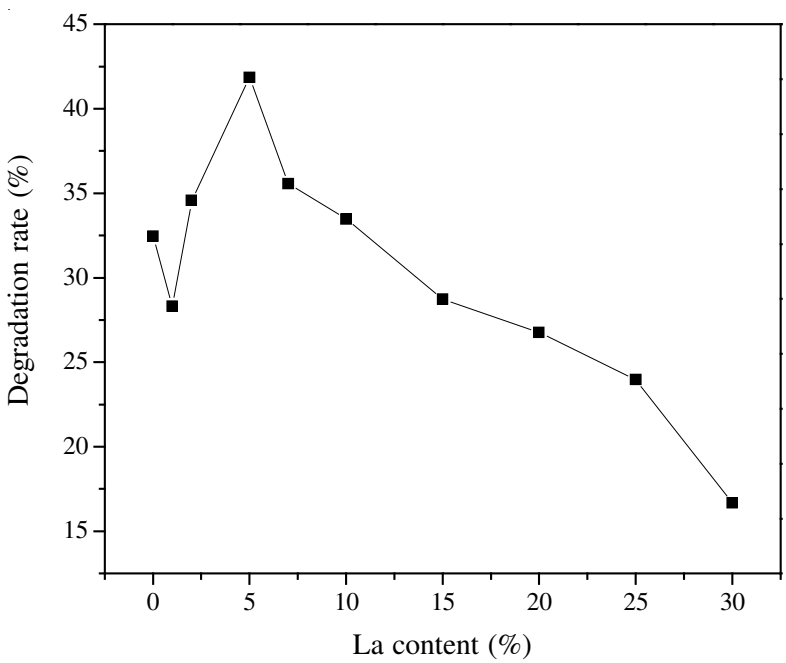

Fig. 4. Effect of La content in strontium titanate on the degradation rate of methyl orange

The strontium titanate doped with more than $10 \% \mathrm{La}$ undergoes drastic activity declining. This can be attributed to low activity of the produced $\mathrm{Sr}_{0.8} \mathrm{La}_{0.2} \mathrm{TiO}_{3}$ and an other reason may be the crystalline defects produced at high La content ${ }^{16,17}$. These defects can be the recombination center for charge carriers and reduce photocatalytic activity. The strontium titanate doped with $5 \%$ La showed the optimum photocatalytic activity.

Photocatalytic activity of strontium titanate doped with $5 \%$ La is compared with strontium titanate without La (Fig. 5). Adsorption rate of methyl orange on the two materials is not more than $3 \%$ after $2 \mathrm{~h}$. The doped strontium titanate has much improved activity than the sample without La doping. After $2 \mathrm{~h}$ of irradiation, degradation rate of methyl orange is as high as $90.5 \%$ on the $5 \%$ La doped strontium titanate.

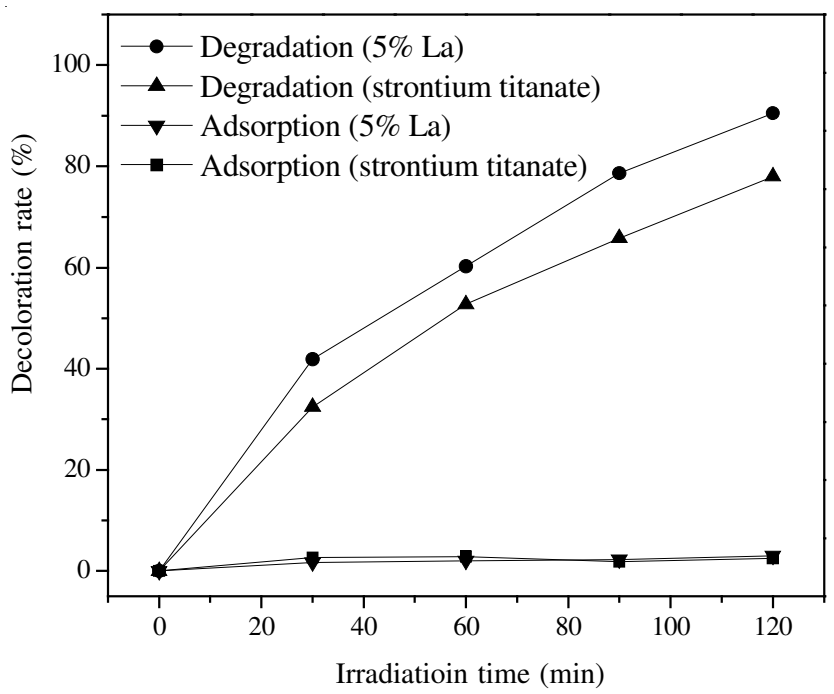

Fig. 5. Effect of irradiation time on the decoloration rate of methyl orange

\section{Conclusion}

The effects of La doping in strontium-titanium on phase composition, structure and photocatalytic activity were studied. The samples present various surface morphologies as the factor of La doping content. The substances in the produced samples 
varied in accordance to La doping content. The strontium titanate doped with $5 \%$ La showed the optimum photocatalytic activity. The doped strontium titanate has much improved activity than the sample without La doping.

\section{ACKNOWLEDGEMENTS}

This work was supported by the National Natural Science Foundation of China (No. 41071161), National Key Basic Research Foundation of China (2011CB403202) and Liaoning Science and Technology Project (2010229002).

\section{REFERENCES}

1. H.W. Eng, P.W. Barnes, B.M. Auer and M. Woodward, Solid State Chem., 175, 94 (2003).

2. H. Kato and A. Kudo, Photochem. Photobiol. A, 145, 129 (2001).

3. E.M. Sbaolsky, A.R. Jmae, S. Kwom, S. Trolier-McKinstry and G.L. Messing, Appl. Phys. Lett., 78, 2551 (2001).

4. K. Akuto and Y. Sakurai, J. Electrochem. Soc., 148, A121 (2001).
5. M. Avudaithai and T.R.N. Kutty, Mater. Res. Bull., 22, 641 (1987).

6. J.A.I. Joice, G. Ramya, R. Vaithiyanathan, R. Ramakrishnan and T. Sivakumar, Asian J. Chem., 24, 5766 (2012).

7. S. Zhang, J.X. Liu, Y.X. Han, B.C. Chen and X.G. Li, Mater. Sci. Eng. $B, 110,11$ (2004)

8. H.X. Liu, X.Q. Sun, Q.L. Zhao, J. Xiao and S.X. Ouyang, Solid-State Electron., 47, 2295 (2003).

9. J.S. Wang, S. Yin, M. Komatsu, Q.W. Zhang, F. Saito and T. Sato, J. Photochem. Photobiol. A, 165, 149 (2004).

10. X.W. Wang, Z.Y. Zhang and S.X. Zhou, Mater. Sci. Eng. B, 86, 29 (2001).

11. Y. Matsumoto, U. Unal, N. Tanaka, A. Kudo and H. Kato, J. Solid State Chem., 177, 4205 (2004).

12. H. Kadowaki, N. Saito, H. Nishiyama, H. Kobayashi, Y. Shimodaira and Y. Inoue, J. Phys. Chem., 111, 439 (2007).

13. Y. Qin, G. Wang and Y. Wang, Catal. Commun., 8, 926 (2007).

14. K.-D. Kim and T. Khalil, J. Non-Crys. Solids, 195, 218 (1996).

15. Q. Li, H.J. Su and T.W. Tan, Biochem. Eng. J., 38, 212 (2008).

16. T. Ishii, H. Kato and A. Kudo, Photochem. Photobiol. A, 163, 181 (2004).

17. M. Miyauchi, M. Takashio and H. Tobimatsu, Langmuir, 20, 232 (2004). 